\title{
Banana Peel as Biosorbent for Removal of Brilliant Green from Aqueous Solutions
}

\author{
Elvis Fosso-Kankeu, Enoch Akinbiyi Akinpelu and Marcus Quintus Keulder
}

\begin{abstract}
Availability of quality water for drinking purposes is important for the health and well-being of humans. The discharge of effluents containing dyes to water bodies increase the toxicity resulting in environmental pollution thereof. The treatment of water contaminated by dyes is thus essential. However, due to the intricate structure of many dyes, the treatment of water polluted by these chemicals is difficult and expensive. In this study, the suitability of banana peel to act as adsorbent for the removal of brilliant green, a cationic dye, from aqueous solutions was tested. The banana peel was characterized by Fourier transform infrared spectroscopy (FT-IR). The removal efficiency of brilliant green by banana peel was tested by varying the contact time between the adsorbent and solution and the temperature at which the process was allowed to occur. The adsorption behaviour was described using the pseudo-first and pseudo-second order kinetic models. It was found that banana peel may be considered adequate for the removal of cationic dyes, such as brilliant green, from wastewater.
\end{abstract}

Keywords-Adsorption; Banana peel; Brilliant green; Cationic dyes; FT-IR

\section{INTRODUCTION}

Dyes can be generally classified as anionic or cationic, with the latter considered to be the more toxic of the two [1]. Decolorization of water in industry is important for the provision of drinking water of adequate quality [1]. Chemicals that add color to water usually have complex structures, which causes the removal thereof from water to be difficult and expensive [1].

Elvis Fosso-Kankeu is with Water Pollution Monitoring and Remediation Initiatives Research Group, School of Chemical and Minerals Engineering, North-West University, Potchefstroom-South Africa.

Marcus Quintus Keulder is with Water Pollution Monitoring and Remediation Initiatives Research Group, School of Chemical and Minerals Engineering, North-West University, Potchefstroom-South Africa..

Enoch Akinbiyi Akinpelu is with Water Pollution Monitoring and Remediation Initiatives Research Group, School of Chemical and Minerals Engineering, North-West University, Potchefstroom-South Africa.
Brilliant green is a cationic dye used for several objectives, such as serving as a biological stain, dermatological agent and veterinary medicine, as well as having broad use in the textile and paper printing industries [2]. The dye is harmful to the skin, eyes and digestion system and, if inhaled, can be poisonous to the lungs [3]. Furthermore, carbon dioxide, sulfur oxides and nitrogen oxides may be produced as the chemical degenerates [3]. The removal of brilliant green from water is thus necessitated [4].

The removal of dyes from textile wastewater can occur via physical, chemical or physicochemical processes [5]. Physical treatment methods are principally used for the primary treatment of wastewater and include filtration and separation, dilution, gamma irradiation, etc. [5]. Chemical treatment techniques include oxidation, reduction, chlorination, etc. Physicochemical treatment processes include adsorption, coagulation, flocculation, ion exchange, reverse osmosis etc. [5].

A biosorbent is defined as an adsorbent which consists of biomass [6]. Biosorption provides a cost-effective and safe way for the treatment of wastewater [6]. Biosorption is economical relative to many other available treatment options [6],[7], as the preparation of adsorbents from biowaste is moderately inexpensive and the generated adsorbent is reusable in many instances [6]. Compared to many other wastewater treatment options, biosorption is beneficial as it is uncomplicated, produces less waste and is generally very efficient in removal of contaminants from water [6]. Less chemicals are required than in the case with chemical treatment, which reduces the chances of environmental pollution that can be caused by the chemicals [7],[8].

Banana peels appear to be suitable as choice for biosorbent and is an attractive option for the development of a wastewater treatment option. It is a plant-based waste and generally available locally in many areas, consequently it is an inexpensive raw material [8]. The use of banana peel in wastewater treatment methods will provide a more economical means of purifying water, as less expensive chemicals or technology will be required [8].

Banana peels exhibit several properties adequate for the treatment of wastewater. The fibers in banana peel, which constitute approximately $40 \%$ of the peel, have shown to have high water selectivity, which will be advantageous for water purification purposes [1]. In comparison, less chemicals are required to guarantee peels are adequate for wastewater purification purposes; this decreases the chances of further 
environmental pollution by introducing less chemicals to the environment when the membrane is used [8].

The purpose of this study was to investigate the effectiveness of banana peel for the adsorption of brilliant green from aqueous solution. The chemical composition of banana peel was studied by Fourier transform infrared spectroscopy (FT-IR). The effect of contact time between adsorbent and solution and temperature on the removal efficiency were studied under continuous stirring. The results were modelled with two different kinetic models, namely pseudo-first order and pseudo second order.

\section{EXPERIMENTAL}

\section{A. Materials}

Ripe and unripe bananas were bought from local supermarkets in the Potchefstroom-area in North West, South-Africa.

The brilliant green used for experiments were obtained from Sigma Aldrich, South Africa. Brilliant green solutions were prepared using deionized water.

\section{B. Preparation of Adsorbent}

The bananas were peeled. The peels were cut into reaps and washed with deionized water to remove any contaminants that may be present on the surface. The banana peels were dried in an oven until completely dry. The peels were crushed into smaller pieces using a bowl and mortar, followed by the pulverizing thereof into a powder using a coffee bean grinder.

The peels were separated according to particle size. Meshes with pass sizes of $106 \mu \mathrm{m}, 250 \mu \mathrm{m}, 500 \mu \mathrm{m}, 710 \mu \mathrm{m}$ and 1.18 $\mathrm{mm}$ were used to accomplish this. The peels were sieved using a sieve shaker for a period of one hour. The banana peel powder on each sieve were collected and stored separately.

For the adsorption of brilliant green, a mixture of the banana peel powders with the smallest size fractions were used, in other words, a mixture of the powder with a pass size of $250 \mu \mathrm{m}$ and $106 \mu \mathrm{m}$ were used.

The banana peel powder was washed with water to remove any colorants to ensure it does not add color to any substance it is added to. Amounts of banana peel powder were placed in 250 $\mathrm{mL}$ deionized water in an Erlenmeyer flask, which was then put on an orbital shaker and allowed to stir for thirty minutes at a rotational speed of $200 \mathrm{rpm}$. The solution was then transferred from the Erlenmeyer flask to various centrifuge tubes. The solution was centrifuged at a rotational speed of $4000 \mathrm{rpm}$ for a period of five minutes, which caused the banana peels to settle at the bottom of the centrifuge tubes. The liquid resting on top of the powder was decanted from the centrifuge tube and was discarded. The banana peel powder was transferred from the centrifuge tube to a pan. After all banana peel powder in the original solution had been transferred to the pan, the pan was placed in an oven and allowed to dry.

The dried banana peel powder was collected from the pan and stored in an air-tight container.

\section{Preparation of Dye Solutions}

Stock solutions of brilliant green with a concentration of 250 $\mathrm{mg} / \mathrm{L}$ were prepared by dissolving $0.0625 \mathrm{~g}$ of dye in $250 \mathrm{~mL}$ deionized water or by dissolving $0.1250 \mathrm{~g}$ of dye in $500 \mathrm{~mL}$ deionized water. Volumes of the stock solution were diluted with deionized water to prepare dye solutions with different desired concentrations. Solutions with dye concentrations of 50 $\mathrm{mg} / \mathrm{L}, 75 \mathrm{mg} / \mathrm{L}, 100 \mathrm{mg} / \mathrm{L}, 125 \mathrm{mg} / \mathrm{L}, 150 \mathrm{mg} / \mathrm{L}, 175 \mathrm{mg} / \mathrm{L}$ and $200 \mathrm{mg} / \mathrm{L}$ were used for experiments. Dye solutions with a concentration of $10 \mathrm{mg} / \mathrm{L}, 25 \mathrm{mg} / \mathrm{L}, 50 \mathrm{mg} / \mathrm{L}, 100 \mathrm{mg} / \mathrm{L}$ and $150 \mathrm{mg} / \mathrm{L}$ were required to obtain the necessary calibration curves.

\section{Calibration of Brilliant Green Standard Curve}

Stock solutions for brilliant green with a dye concentration of $250 \mathrm{mg} / \mathrm{L}$ were prepared and diluted to obtain solutions with respective dye concentration of $10 \mathrm{mg} / \mathrm{L}, 25 \mathrm{mg} / \mathrm{L}, 50 \mathrm{mg} / \mathrm{L}$, $100 \mathrm{mg} / \mathrm{L}$ and $150 \mathrm{mg} / \mathrm{L}$. A UV-Visible spectrophotometer (model: Genesys 10S UV-Vis) was used to measure the absorbance of the diluted solutions at a wavelength of $425 \mathrm{~nm}$ for the brilliant green.

Graphs for absorbance as function of dye concentration for brilliant green was drawn and used as standard curve to measure the dye concentration in all solutions used during experiments. To determine the concentration of dye present in a solution, the absorbance of the solution was measured using the UV-visible spectrophotometer and was then related to the concentration of the dye solution.

\section{E. General Procedure of Experiments}

The banana peels were tested for the adsorption of brilliant green from water. The same general experimental procedure applies for all parameters studied and is discussed subsequently.

Dye solutions with a volume of $100 \mathrm{~mL}$ were used for all experiments, with the dye concentration varying depending on the parameter studied. The $100 \mathrm{~mL}$ dye solution was sampled from a prepared $250 \mathrm{~mL}$ stock solution and placed into a 500 $\mathrm{mL}$ Erlenmeyer flask.

The required amount of banana peel powder was weighed. A mass of $50 \mathrm{mg}$ of banana peel powder was used for all experiments conducted. The size fraction used was a mixture of the banana peel powder with a pass size of $250 \mu \mathrm{m}$ and $106 \mu \mathrm{m}$. The banana peels were washed to remove all colorant and dried prior to use.

The suitable amount of banana peel powder was transferred to the Erlenmeyer flask which contains the dye solution. Hereafter, the Erlenmeyer flask was placed on an orbital shaker and stirred at a rotational speed of $160 \mathrm{rpm}$. The stirring was allowed to commence for a certain period of time and at a certain temperature, which both depended on the particular parameter studied and experiment conducted as well.

The Erlenmeyer flask was removed from the orbital shaker and approximately $30 \mathrm{~mL}$ of the solution was centrifuged. The solution inside the centrifuge tube was centrifuged using a centrifuge (model: Rotofix $32 \mathrm{~A}$ ) at a rotational speed of 4000 rpm for a period of ten minutes to ensure that the adsorbent separates from the rest of the mixture and settles at the bottom of the tube. As much of the solution as possible was transferred to a clean centrifuge tube without relocating any of the adsorbent. The treated solution, which is separated from the 
adsorbent, can be subjected to further tests.

The absorbance of the treated solution was measured using the UV-Vis spectrophotometer. If needed, the treated solution was diluted to ensure its concentration falls into the range of the standard curve. The spectrophotometer related the absorbance to the concentration by utilization of the calibration curve.

\section{F. Effect of Contact Time}

The effect of contact time on the adsorbent's brilliant green removal efficiency was determined by varying the exposure time of the adsorbent to the dye solution. The contact times studied were 20 minutes, 40 minutes, 60 minutes, 80 minutes, 100 minutes and 120 minutes respectively. The general experimental procedure as described above were used to perform experiments.

\section{G. Effect of Temperature}

The effect of temperature on the dye removal efficiency of banana peel was considered by varying the temperature by the following values: $25^{\circ} \mathrm{C}, 35^{\circ} \mathrm{C}, 45^{\circ} \mathrm{C}$ and $55^{\circ} \mathrm{C}$. The general experimental procedure as described previously was used to execute experiments. For each temperature, each experiment was conducted at each different concentration as well.

\section{H. Determination of Effectiveness of Adsorbent}

The amount of adsorbate adsorbed to the adsorbent at any specific time t, denoted by $q_{t}$, was calculated by utilization of (1) [9]. The removal efficiency $(R)$ of the adsorbent on the brilliant green solutions were calculated using (2) [9].

$$
\begin{gathered}
q_{t}=\frac{C_{0}-C_{t}}{m} \cdot V \\
R=\frac{C_{0}-C_{t}}{C_{0}} \cdot 100 \%
\end{gathered}
$$

In (1) and (2), $C_{0}$ is the initial concentration (in $\mathrm{mg} / \mathrm{g}$ ) of the dye in the aqueous solution, $C_{t}$ is the concentration (in $\mathrm{mg} / \mathrm{L}$ ) of the brilliant green solution after treatment with banana peel for a specific time $t, m$ is the mass of the adsorbent (adsorbent dosage) (in $\mathrm{g}$ ) and $V$ is the volume of the dye solution (in $\mathrm{L}$ ).

\section{Characterization of Adsorbent}

The chemical composition of the banana peel was determined with use of Fourier Transform Infrared Spectroscopy (FT-IR).

\section{J. Adsorption Kinetics}

The adsorption kinetics of banana peel adsorbing brilliant green from aqueous solution was studied at a temperature of $25^{\circ} \mathrm{C}$ The following times were selected to vary the contact time between adsorbent and solution: 20, 40, 60, 80, 100 and 120 minutes. For each experiment, $50 \mathrm{mg}$ adsorbent was added to $50 \mathrm{~mL}$ dye solutions and an initial concentration of $150 \mathrm{mg} / \mathrm{L}$ and was subsequently stirred at a rotational speed of $160 \mathrm{rpm}$ for the designated contact time.

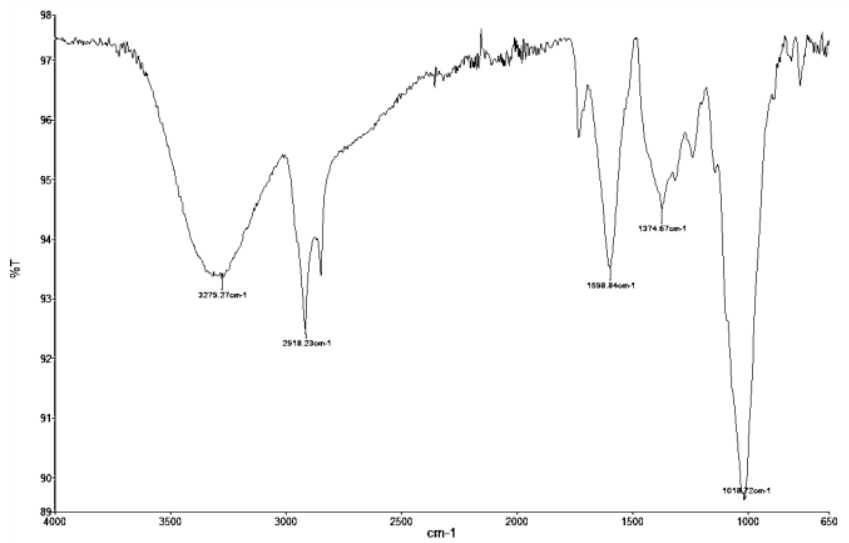

Fig. 1. FT-IR analysis of banana peel.

The pseudo-first order and pseudo-second order kinetic models were utilized to describe the behaviour of the experimental results.

The linear form of the pseudo-first order kinetic model is given in 7 [10]. A plot with $\log \left(q_{e}\right)$ as independent variable and $\log \left(q_{e}-q_{t}\right)$ as dependent variable was used to determine the applicable parameters.

$$
\log \left(q_{e}-q_{t}\right)=-\frac{k_{S 1}}{2.303} \cdot t+\log \left(q_{e}\right)
$$

In (3), $q_{t}$ is the amount of adsorbate adsorbed to the surface of the adsorbent (in $\mathrm{mg} / \mathrm{g}$ ) at any time $t$ (in minutes), $q_{e}$ represents the amount of adsorbate adsorbed on the surface of the adsorbent (in $\mathrm{mg} / \mathrm{g}$ ) at equilibrium and $k_{S I}$ is the rate constant for pseudo-first order adsorption (in $\mathrm{min}^{-1}$ ).

The linear form of the pseudo-second order kinetic model is given in (4) [10]. The related parameters are determined with a plot of $t / q_{t}$ as function of $t$.

$$
\frac{t}{q_{t}}=\frac{1}{q_{e}} \cdot t+\frac{1}{k_{S 2} \cdot q_{e}^{2}}
$$

In (4), $q_{t}$ is the amount of adsorbate adsorbed to the surface of the adsorbent (in $\mathrm{mg} / \mathrm{g}$ ) at any time $\mathrm{t}$ (in minutes), $q_{e}$ is the amount of adsorbate adsorbed to the surface of the adsorbent (in $\mathrm{mg} / \mathrm{g}$ ) at equilibrium and $k_{S 2}$ is the rate constant for pseudo-second order adsorption (in $\mathrm{g} /(\mathrm{mg} \cdot \mathrm{min})$ ).

The amount of adsorbate adsorbed to the surface of the adsorbent at any specific time $\left(q_{t}\right)$ is calculated with (1), while the amount of adsorbate adsorbed to the surface of the adsorbent at equilibrium $\left(q_{e}\right)$ is evaluated with (5) [3].

The amount of adsorbate adsorbed onto the adsorbent at equilibrium $\left(q_{e}\right)$ is given in (5) [4].

$$
q_{e}=\frac{C_{0}-C_{e}}{m} \cdot V
$$

In (5), $C_{0}$ is the initial concentration of brilliant green in solution (in $\mathrm{mg} / \mathrm{L}$ ), $m$ is the mass of the adsorbent (adsorbent dosage) (in $\mathrm{g}$ ) and $V$ is the volume of the dye solution (in $\mathrm{L}$ ). 


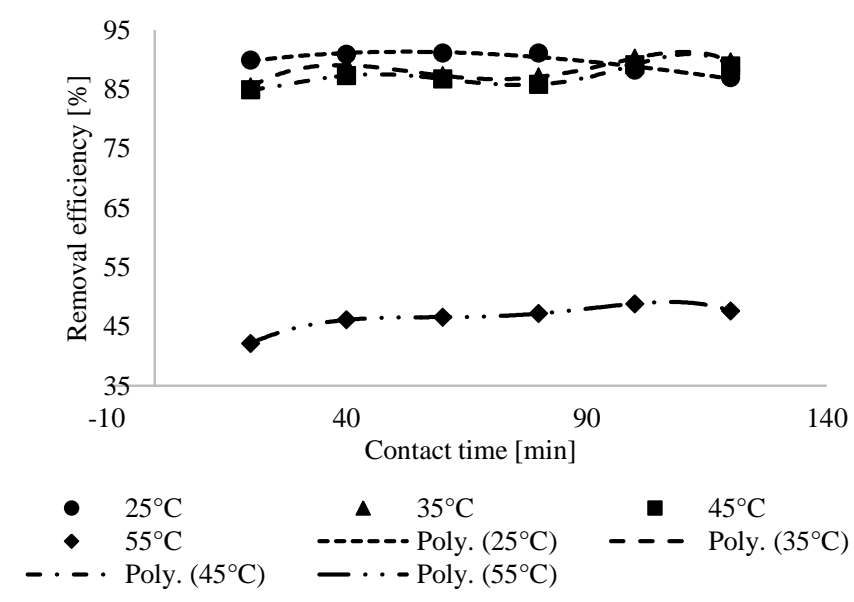

Fig. 2. Effect of contact time on removal efficiency at different temperatures.

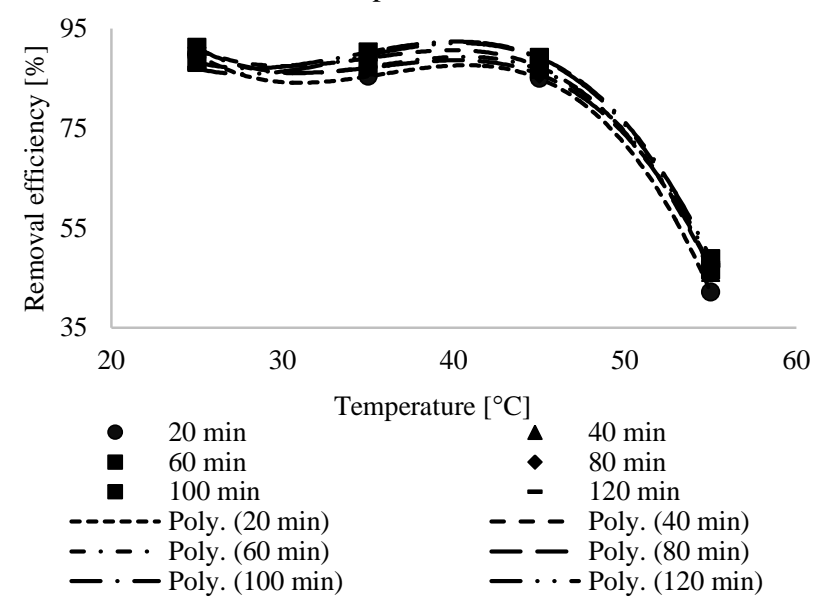

Fig. 3. Effect of temperature on removal efficiency at different contact times.

The appropriateness of each model to predict adsorption behaviour is determined by the coefficient of determination $\left(R^{2}\right)[11]$.

\section{RESULTS \& DISCUSSION}

\section{A. Characterization of Banana Peel Powder with FT-IR}

The FT-IR spectra obtained for the untreated banana peel powder is displayed in Fig. .

The strong, broad adsorption peak at $3279.27 \mathrm{~cm}^{-1}$ falls in the frequency range of $3300-2500 \mathrm{~cm}^{-1}$, which is indicative of the stretching bands of $\mathrm{O}-\mathrm{H}$ groups that are present in the banana peel [12]. The peak also shows the presence of a carboxylic acid.

The adsorption peak at $2918.23 \mathrm{~cm}^{-1}$ suggests the stretching of the bands of two possible groups, namely $\mathrm{O}-\mathrm{H}$ or $\mathrm{N}-\mathrm{H}$, and the possibility of three different compound classes, namely carboxylic acid, alcohol or an amine salt [12].

The bending of a N-H group, which is representative of the presence of an amine, or the stretching of a $\mathrm{C}=\mathrm{C}$ group, which indicates the presence of a cyclic alkene, is presented by the adsorption peak visible at $1598.84 \mathrm{~cm}^{-1}$ [12].

The bending of an $\mathrm{O}-\mathrm{H}$ group is suggested by the adsorption peak found at $1374.67 \mathrm{~cm}^{-1}$ [12]. This suggests the possible presence of a phenol group.

The adsorption peak visible at $1018.72 \mathrm{~cm}^{-1}$ implies the stretching of a C-N group, which indicates the possible presence of an amine group, or the stretching of an S-O group, which suggests the presence of a sulfoxide group [12].

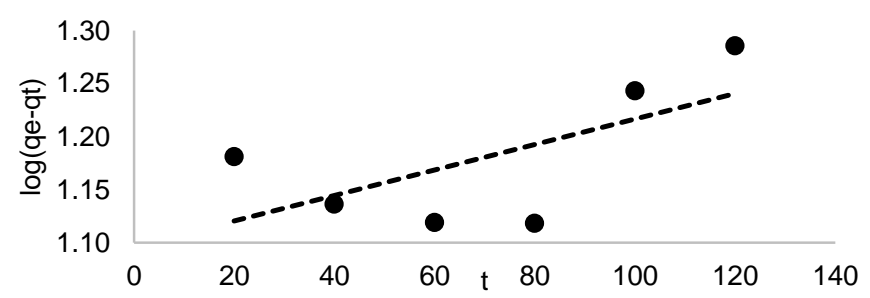

Fig. 4. Pseudo-first order isotherm model for adsorption of brilliant green onto banana peel.

TABLE I. KINETIC PARAMETERS FOR THE ADSORPTION OF BRILLIANT GREEN ONTO BANANA PEEL.

\begin{tabular}{ccc}
\hline Kinetic model & Parameters & Value \\
\hline & $k_{S 1}$ & $-0.0028 \mathrm{~min}^{-1}$ \\
Pseudo-first & $q_{e, \text { exp }}$ & $148.77 \mathrm{mg} / \mathrm{g}$ \\
order & $q_{e, \text { calc }}$ & $2.99 \mathrm{mg} / \mathrm{g}$ \\
& $R^{2}$ & 0.412 \\
\hline & $k_{S 2}$ & -0.0039 \\
Pseudo-second & $q_{e, \text { exp }}$ & $\mathrm{min} \cdot \mathrm{g} / \mathrm{mg}$ \\
order & $q_{e, \text { calc }}$ & $148.77 \mathrm{mg} / \mathrm{g}$ \\
& $R^{2}$ & $128.91 \mathrm{mg} / \mathrm{g}$ \\
& & 0.999 \\
\hline
\end{tabular}

\section{B. Effect of Contact Time \& Temperature on Removal Efficiency}

The effect of contact time and temperature on the removal efficiency of brilliant green by banana peel was tested simultaneously. Contact times studied were 20, 40, 60, 80, 100 and 120 minutes, while temperatures examined were $25^{\circ} \mathrm{C}$, $35^{\circ} \mathrm{C}, 45^{\circ} \mathrm{C}$ and $55^{\circ} \mathrm{C}$. The removal efficiency as a function of contact time for different temperatures is presented in Fig. 2, while the removal efficiency as a function of temperature for different contact times are shown in Fig. 3. From both Fig. 2 and Fig 3. it is evident that the range of the removal efficiency of the adsorbent at $55^{\circ} \mathrm{C}$ differs significantly from the range of removal efficiencies at other temperatures.

From Fig. 2 and Fig. 3, it can be observed that the optimum temperature is $25^{\circ} \mathrm{C}$. The removal efficiency ranges between $84 \%$ and $92 \%$ for all contact times at the lower three temperatures, while the removal efficiency falls between $42 \%$ and $49 \%$ for the contact times at a temperature of $55^{\circ} \mathrm{C}$.

The removal efficiencies as a function of contact time at temperatures of $25^{\circ} \mathrm{C}, 35^{\circ} \mathrm{C}$ and $45^{\circ} \mathrm{C}$ are compared in Fig. 2 . At a temperature of $25^{\circ} \mathrm{C}$, the removal efficiency increases with an increase in contact time and reaches maximum efficiency at a contact time of 60 minutes. The removal efficiency remains approximately constant for throughout the 120 minutes contact times. At a temperature of $35^{\circ} \mathrm{C}$ and $45^{\circ} \mathrm{C}$, the removal efficiency increases slightly as the contact time increases from 20 minutes to 40 minutes, subsequently decreases up to a 
contact time of 80 minutes and afterwards increases, where it reaches a maximum at a contact time of 100 minutes and subsequently starts decreasing.

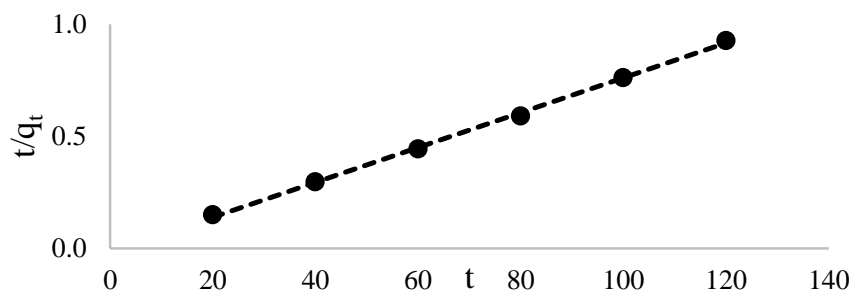

Fig. 5. Pseudo-second order behaviour for adsorption of brilliant green onto banana peel.

The removal efficiencies as a function of temperature for the temperatures of $25^{\circ} \mathrm{C}, 35^{\circ} \mathrm{C}$ and $45^{\circ} \mathrm{C}$ at different contact times are given in Fig. 3. For contact times of 20, 40, 60 and 80 minutes, the removal efficiency decreases with an increase in temperature, while the removal efficiency increases from $25^{\circ} \mathrm{C}$ to $35^{\circ} \mathrm{C}$ and decreases slightly from of $35^{\circ} \mathrm{C}$ to $45^{\circ} \mathrm{C}$.

From Fig. 2 and Fig. 3, it is evident that the highest removal efficiency corresponds to a contact time of 60 minutes at a temperature of $25^{\circ} \mathrm{C}$, while a contact time of 40 minutes at the same temperature results in the same approximate removal efficiency.

\section{Adsorption Kinetics Studies}

The kinetic parameters for pseudo-first order adsorption was determined from a plot of $t$, as independent variable, versus $\log \left(q_{e^{-}} q_{t}\right)$, as dependent variable, as described in [7]. A plot of $t$, the independent variable, versus $t / q_{t}$, the dependent variable, was utilised to determine the kinetic parameters for pseudo-second order behaviour, as depicted in [9]. The plots of the former and latter are given in Fig. 4 and Fig. 5 respectively. The determined values of the kinetic parameters are displayed in TABLE I.

The coefficient of determination $\left(\mathrm{R}^{2}\right)$ is considered to determine the suitability of each model to predict the behaviour of adsorption. Examining the values of $R^{2}$ in TABLE I, it is evident that the pseudo-first order model is not appropriate for the prediction of adsorption data, as the value of $R^{2}$ is very low. The inadequacy of the model is further demonstrated by the significant difference in the calculated and experimental amounts of adsorbate adsorbed to the adsorbent $\left(q_{e}\right)$. The adsorption behaviour may be described fittingly with the pseudo-second order model, as apparent by the $R^{2}$ value near to unity. This therefore implies that the adsorption of brilliant green occurs through a chemisorption mechanism [.

\section{CONCLUSION}

The suitability of banana peel as adsorbent of brilliant green from aqueous solutions were investigated in this study.

An increase in contact time between adsorbent and dye solution resulted in decrease relatively constant adsorption efficiency overtime, implying that there is a fast adsorption of brilliant green resulting into the saturation of the binding surface after 40 minutes of exposure. For productive purposes, a contact time of 40 minutes will be most optimal.
Temperatures of $25^{\circ} \mathrm{C}, 35^{\circ} \mathrm{C}$ and $45^{\circ} \mathrm{C}$ all lead to removal efficiencies of more than $80 \%$, while a temperature of $55^{\circ} \mathrm{C}$ results in very low removal efficiency. A temperature of $25^{\circ} \mathrm{C}$ was found to be the most optimal temperature, both in removal efficiency and economically.

The adsorption behaviour and capacity of banana peel was found to be modelled adequately with the pseudo-second order kinetic model, while the pseudo-first order kinetic model does not describe the data adequately.

From the results obtained, it can be concluded that banana peel may serve as sufficient adsorbent for brilliant green from wastewater. It may be further assumed that banana peel will be adequate for the removal of cationic dyes in general.

\section{ACKNOWLEDGMENT}

The authors are thankful to the North-West University for the general support and to $\mathrm{Mr} \mathrm{N}$ Lemmer for the laboratory assistance.

\section{REFERENCES}

[1] O. J. Hao, H. Kim, and P. C. Chiang, "Decolorization of wastewater," Critical reviews in environmental science and technology, vol. 30, no. 4, pp. 449-505, 2000. https://doi.org/10.1080/10643380091184237

[2] B. K. Nandi, A. Goswami, and M. K. Purkait, "Adsorption characteristics of brilliant green dye on kaolin," Journal of hazardous materials, vol. 161 , no. 1 , pp. 387-395, Jan $152009 .$. https://doi.org/10.1016/j.jhazmat.2008.03.110

[3] M. A. Salem, R. G. Elsharkawy, and M. F. Hablas, "Adsorption of brilliant green dye by polyaniline/silver nanocomposite: kinetic, equilibrium, and thermodynamic studies," European polymer journal, vol. 75 , pp. 577-590, 2016. https://doi.org/10.1016/j.eurpolymj.2015.12.027

[4] M. S. U. Rehman et al., "Adsorption of Brilliant Green dye from aqueous solution onto red clay," Chemical engineering journal, vol. 228, pp. 54-62, 2013.

https://doi.org/10.1016/j.cej.2013.04.094

[5] H. S. Rai, M. S. Bhattacharyya, J. Singh, T. K. Bansal, P. Vats, and U. C. Banerjee, "Removal of dyes from the effluent of textile and dyestuff manufacturing industry: a review of emerging techniques with reference to biological treatment," Critical reviews in environmental science and technology, vol. 35, no. 3, pp. 219-238, 2005. https://doi.org/10.1080/10643380590917932

[6] C. A. Reddy, N. Prashanthi, P. H. Babu, and J. S. Mahale, "Banana peel as a biosorbent in removal of nitrate from water," International advanced research journal in science, engineering and technology, vol. 2, no. 10, 2015. https://doi.org/10.17148/IARJSET.2015.21020

[7] T. Zaidan, E. Salah, and M. Waheed, "Banana peel as removal agent for sulfide from sulfur springs water," Civil and environmental research, vol. 3, no. 10, pp. 27-36, 2013.

[8] S. Datta, S. Karmoker, and T. Sowgath, "Membrane development from banana peel fibers for waste water treatment at low cost," presented at the Conference, Environmental division; core programming topic at the 2012 AIChE annual meeting, Pittsburgh, PA, 2012.

[9] M. Ghaedi et al., "A novel acorn based adsorbent for the removal of brilliant green," Desalination, vol. 281, pp. 226-233, 2011. https://doi.org/10.1016/j.desal.2011.07.068

[10] Y. S. Ho and G. McKay, "Pseudo-second order model for sorption processes," Process biochemistry, vol. 34, no. 5, pp. 451-465, 1999. https://doi.org/10.1016/S0032-9592(98)00112-5

[11] E. Fosso-Kankeu, F. Waanders, and C. L. Fourie, "Adsorption of Congo Red by surfactant-impregnated bentonite clay," Desalination and water treatment, vol. 57, no. 57, pp. 1-9, 2016. https://doi.org/10.1080/19443994.2016.1177599

[12] Merck KGaA. "IR spectrum table \& chart." https://www.sigmaaldrich.com/technical-documents/articles/biology/ir-s pectrum-table.html (accessed 4 October 2019, 2019). 
[13] Elvis Fosso-Kankeu. 2019. Nano and Bio-based Technologies for wastewater treatment: Prediction and Control Tools for the dispersion of Pollutants in the Environment. Wiley Scrivener. ISBN: 978-1-119-57709-6. Pp 301-336.

[14] Elvis Fosso-Kankeu. 2019. New Horizons in Wastewaters Management: Emerging Monitoring and Remediation Strategies. Nova Science Publishers. ISBN: 978-1-53615-659-1.

[15] Fosso-Kankeu E., Potgieter J. and Waanders F.B. 2019. Removal of malachite green and toluidine blue dyes from aqueous solution using a clay-biochar composite of bentonite and sweet sorghum bagasse. International Journal of Applied Engineering Research. 14(6): 1324-1333.

[16] N Kumar, E Fosso-Kankeu, SS Ray. 2019. Achieving controllable MoS2 nanostructures with increased interlayer spacing for efficient removal of $\mathrm{Pb}$ (II) from aquatic systems. ACS Applied Materials and Interfaces. 11: 19141-19155. https://doi.org/10.1021/acsami.9b03853

[17] E Fosso-Kankeu, R Weideman, D Moyakhe, FB Waanders, M Le Roux, QP Campbell. 2019. Hydrothermal preparation of biochar from spent coffee grounds, and its application for the removal of cadmium from coal tailings leachate. The Journal of the Southern African Institute of Mining and Metallurgy. 119: 607-612. https://doi.org/10.17159/2411-9717/449/2019

[18] R Gusain, N Kumar, E Fosso-Kankeu, SS Ray. 2019. Efficient removal of $\mathrm{Pb}$ (II) and $\mathrm{Cd}$ (II) from industrial mine water by a hierarchical MoS2/SH-MWCNT nanocomposite. ACS Omega. 4: 13922-13935. https://doi.org/10.1021/acsomega.9b01603

[19] E. Fosso-Kankeu, A. Mulaba-Bafubiandi, B.B. Mamba, L. Marjanovic, T.G. Barnard, A comprehensive study of physical and physiological parameters that affect biosorption of metal pollutants from aqueous solutions. Journal of Physics and Chemistry of the Earth, Vol. 35, pp. 672-678, 2010. https://doi.org/10.1016/j.pce.2010.07.008

[20] E. Fosso-Kankeu, A.F. Mulaba-Bafubiandi, B.B. Mamba and T.G. Barnard, Prediction of metal-adsorption behaviour in the remediation of water contamination using indigenous microorganisms. Journal of Environmental Management. Vol. 92, no. 10, pp. 2786-2793, 2011. https://doi.org/10.1016/j.jenvman.2011.06.025

[21] H. Mittal, E. Fosso-Kankeu, Shivani B. Mishra, Ajay K. Mishra, Biosorption potential of Gum ghatti-g-poly (acrylic acid) and susceptibility to biodegradation by $\mathrm{B}$. subtilis. International Journal of Biological Macromolecules. Vol. 62, pp. 370-378, 2013. https://doi.org/10.1016/j.ijbiomac.2013.09.023

[22] E. Fosso-Kankeu, H. Mittal, S.B. Mishra, A.K. Mishra, Gum ghatti and acrylic acid based biodegradable hydrogels for the effective adsorption of cationic dyes. Journal of Industrial and Engineering Chemistry. Vol. 22, pp. 171-178, 2015. https://doi.org/10.1016/j.jiec.2014.07.007

[23] E. Fosso-Kankeu, H. Mittal, F. Waanders, I.O. Ntwampe, S.S. Ray, Preparation and characterization of gum karaya hydrogel nanocomposite flocculant for metal ions removal from mine effluents. International Journal of Environmental Science and Technology. Vol. 13, pp. 711-724, 2016. https://doi.org/10.1007/s13762-015-0915-x

[24] E. Fosso-Kankeu, F. Waanders, E. Maloy, Copolymerization of ethyl acrylate onto guar gum for the adsorption of $\mathrm{Mg}$ (II) and $\mathrm{Ca}$ (II) ions. Desalination and Water Treatment. doi: 10.1080/19443994.2016.1165147: pp. 1-10, 2016.

[25] E. Fosso-Kankeu, F. Waanders, C.L. Fourie, Adsorption of Congo Red by surfactant-impregnated bentonite clay. Desalination and Water Treatment. doi: 10.1080/19443994.2016.1177599: pp. 1-9, 2016.

[26] E. Fosso-Kankeu, A.F. Mulaba-Bafubiandi, L.A. Piater, M.G. Tlou, Cloning of the cnr operon into a strain of Bacillaceae bacterium for the development of a suitable biosorbent. World Journal of Microbiology and Biotechnology. DOI 10.1007/s11274-016-2069-5. 2016.

[27] E. Fosso-Kankeu, H. Mittal, F. Waanders, S.S. Ray, Thermodynamic properties and adsorption behaviour of hydrogel nanocomposites for cadmium removal from mine effluents. Journal of Industrial and Engineering Chemistry. Vol. 48, pp. 151-161, 2017. https://doi.org/10.1016/j.jiec.2016.12.033

[28] E. Fosso-Kankeu, F.B. Waanders, F.W. Steyn, Removal of Cr(VI) and $\mathrm{Zn}$ (II) from an aqueous solution using an organic-inorganic composite of bentonite-biochar-hematite. Desalination and Water Treatment. Vol. 59, pp. 144-153, 2017.

https://doi.org/10.5004/dwt.2017.0059
[29] A. Leudjo Taka, E. Fosso-Kankeu, K. Pillay, X. Yangkou Mbianda, Removal of cobalt and lead ions from wastewater samples using an insoluble nanosponge biopolymer composite: Adsorption isotherms, kinetics, thermodynamics and regeneration studies. Environmental Science and Pollution Research. 2018.

[30] E Fosso-Kankeu, R Weideman, D Moyakhe, F Waanders, Q Campbell. 2019. Thermodynamic study of the adsorption performance of spent coffee beans for the removal of cadmium from coal tailing leachates. IMWA 2019 Conference "Mine Water - Technological and Ecological Challenges". 15-19 July 2019, Perm, Russia. Elena Khayrulina and Christian Wolkersdorfer. ISBN: 978-5-91252-145-4. Pp 184-188.

[31] E. Fosso-Kankeu, F. Waanders, and J.J. Venter, Impact of synthetic clay as filling agents on the dye adsorption capacity of hydrogel. $9^{\text {th }}$ Int'l Conference on Advances in Science, Engineering, Technology \& Waste Management (ASETWM-17). 27-28 November 2017, Parys, South Africa. Editors: F. Waanders, E. Fosso-Kankeu, B. Topcuoglu, M. Plaisent, Y. Thaweesak. ISBN: 978-81-934174-6-1. Pp. 37-43. 2017.

[32] Elvis Fosso-Kankeu, Martin Joseph Spiro, Frans Waanders, Neeraj Kumar, Suprakas Sinha Ray and Nico Lemmer. 2018. Hydrothermal Synthesis, Characterization and Adsorption Testing of $\mathrm{MoS}_{2}$-Zeolite for the Removal of Lead in an Aqueous Solution. Editors. Elvis Fosso-Kankeu, Frans Waansders, Michel Plaisent. 10th Int'l Conference on Advances in Science, Engineering, Technology \& Healthcare (ASETH-18) Nov. 19-20, 2018 Cape Town (South Africa). ISBN: 978-81-938365-2-1. Vol II. Pp 160-165. 